\title{
Design Principles to Support Physics and Engineering Learning in Complementary Classrooms and Field Trip Activities
}

\author{
Alexandria Muller ${ }^{1}$, Ron Skinner ${ }^{2}$, Tarah Connolly ${ }^{2}$, Devon M. Christman ${ }^{1}$, Danielle B. Harlow ${ }^{1}$ \\ ${ }^{I}$ Education, University of California at Santa Barbara, Santa Barbara, CA, 93106 and \\ ${ }^{2}$ MOXI, The Wolf Museum of Exploration + Innovation, 125 State Street, Santa Barbara, CA, 93101
}

We present design principles for leveraging the affordances of schools and an interactive physical science museum to design curriculum modules that result in students learning physics through the practices of science and engineering. The modules include a field trip program and pre and post activities implemented in elementary school classrooms. The design principles are the result of research conducted during the first two years of a three-year design-based implementation research (DBIR) project and conducted through a long term Research-Practice Partnership (RPP) and on iterative development and testing the field trips and activities with 18 classrooms ranging from grades 1 through 6 and representing a range of demographics. 


\section{INTRODUCTION}

Informal Physics Education Research (IPER) is a growing research field that includes physics outreach, physics learning in museums, and other types of public science communication [1-5]. Many of these programs focus on the youngest learners who are developing understandings of physical science and attitudes towards physics that will shape their future choices and experiences with physics. Along with this is a growing recognition of the value of partnerships and STEM ecosystems that support student learning by creating new opportunities for learning that leverage the affordances of multiple types of institutions [6,7].

One way that multiple institutions support student learning is when classroom teachers take students on field trips to science museums to complement their learning in schools. Results of research on the value of field trips for science learning is mixed. Multiple studies point to positive impacts [8-10], while others caution that the brief nature of the trips limits the potential learning gains [11]. Of particular concern to our work is the finding that, while teachers report intending to connect field trip experiences to the classroom curriculum, in actual practice, it is more common for teachers to treat field trips as separate learning experiences with limited explicit connections to classroom activities [12], even though we know that activities conducted in students' classrooms before and after a field trip can increase the benefits of field trips. Pre-visit activities provide opportunities for teachers to elicit students' ideas and provide experiences to develop knowledge that can be leveraged during field trips, making the field trip a more productive learning environment while post-visit activities allow students to expand upon their field trip experience [12-15].

We explored how to effectively design modules of activities that leveraged the unique affordances of schools and museums to result in students engaging in practices of science and engineering. The context in which we explored this question was developing curricular modules which consisted of an engineering-focused field trip program centered around a physics phenomenon at an interactive science center and complementary science and engineering activities to be conducted in K-8 classrooms before and after the field trip.

Our understanding of effective learning was informed by the construct of identity work $[16,17]$ which suggests that participating in specific discourse and social practices contributes to productive STEM identities. That is, engaging in practices associated with STEM disciplines supports the development of positive identities as STEM learners. The goal of engaging students in STEM practices aligns with recommendations of the Next Generation Science Standards [18].

\section{RESEARCH METHODS}

This work was conducted through a Research-Practice Partnership (RPP) [2, 19] between a university and a new in- teractive science center that focuses on physical science content and is informed by PER and research on children's science learning. This partnership brings together faculty and graduate students with expertise in research methods, science education, and teacher education and museum leaders and practitioners with expertise in informal science education. We follow a Design-Based Implementation Research (DBIR) model $[20,21]$ to investigate the problem of practice of developing modules of field trip and classroom activities that met the needs of local teachers. Consistent with DBIR, our work involves participatory research and the knowledge developed includes design principles that build our capacity for future development. The design principles presented here were developed and revised concurrently with the development and testing of the modules.

Our development, testing and implementation process consists of four stages, each with involvement from the research and museum staff. In the first stage, we brainstorm field trip programs that meet the needs of local teachers and leverage the museum's exhibits and resources and develop activities. We then test and revise the field trip program at the museum and develop learning goals for the classroom activities and begin testing some ideas for pre- and post-activities with visitors at the museum. In stage three, we implement the preand post-activities in classrooms and solicit feedback from teachers. In the fourth stage, classroom teachers implement the pre- and post-activities and provide additional feedback.

While the majority of the module development process was done by university and museum staff, the needs and expectations of teachers were elicited and valued. Teachers were invited to provide feedback through surveys, interviews, and informal conversations at multiple points throughout their participation. Their feedback, in combination with classroom observations, informed improvement of subsequent iterations of the modules. Feedback included how to better connect to math, science and literacy standards, modification to make activities appropriate for respective grade levels and suggestions to improve the materials for ease of use by teachers.

Each module consists of two pre-activities completed in the classroom to provide experiences to support students in engaging in an engineering design challenge presented in a subsequent field trip, the field trip activity, and a post-activity in the classroom to reflect and expand upon the learning from the previous activities. Each of these activities is designed to take 50 minutes. Field trip activities are led by museum educators and classroom activities are designed to be led by classroom teachers. Thus far, we have developed and tested two modules and are in the second stage of a third module and first stage of three others. The work here focuses on the first two modules which are summarized in Table 1. More details can be found in [22, 23].

The field trip programs were implemented with over 200 classrooms over the course of two years. Of these, 27 classrooms (ranging from Kindergarten to grade 6, age 5-12) from three focus schools participated in the full modules (field trip activities plus the three classroom based activities) and 


\begin{tabular}{|c|c|c|}
\hline $\begin{array}{l}\text { Activity } \\
\text { (location) }\end{array}$ & $\begin{array}{l}\text { Module 1: Riding the Rising Air } \\
\text { (physics focus: Forces and Motion) }\end{array}$ & $\begin{array}{l}\text { Module 2: Greenhouse on the Moon } \\
\text { (physics focus: Light and waves) }\end{array}$ \\
\hline $\begin{array}{l}\text { Pre-1 } \\
\text { (classroom) }\end{array}$ & $\begin{array}{l}\text { Students constructed three different sized } \\
\text { parachutes to test the relationship between } \\
\text { surface area of a canopy and the rate of fall }\end{array}$ & $\begin{array}{l}\text { Students observed colored images by viewing through differ- } \\
\text { ent colored plastic films and investigated how filters (colored } \\
\text { films) impacted the colors that were transmitted. }\end{array}$ \\
\hline $\begin{array}{l}\text { Pre-2 } \\
\text { (classroom) }\end{array}$ & $\begin{array}{l}\text { Students designed their own craft to help slow } \\
\text { the fall of a washer and iterated on their design }\end{array}$ & $\begin{array}{l}\text { Students used their observations from pre- } 1 \text { to deduce what } \\
\text { the original colors of a colored image sealed behind a red } \\
\text { and a blue plastic film were. Students then designed coded } \\
\text { messages using markers that could only be revealed when } \\
\text { placed behind a red or blue film. }\end{array}$ \\
\hline $\begin{array}{l}\text { Fieldtrip } \\
\text { (museum) }\end{array}$ & $\begin{array}{l}\text { Design challenge: Designing and constructing } \\
\text { a craft that could hover in an upward column } \\
\text { of moving air while carrying a small washer or } \\
\text { penny }\end{array}$ & $\begin{array}{l}\text { Design challenge: Design and construct a "patch" for a } \\
\text { greenhouse on the moon that would allow } 500 \text { lumens and } \\
\text { sufficient heat to pass through to maintain a temperature } \\
23.8^{\circ} \mathrm{C} / 73^{\circ} \mathrm{F} \text {. }\end{array}$ \\
\hline $\begin{array}{l}\text { Post-1 } \\
\text { (classroom) }\end{array}$ & $\begin{array}{l}\text { Using "blueprints" of craft designed in field trip } \\
\text { by a classmate, then attempted to recreate the ve- } \\
\text { hicle and modify it for the classroom environ- } \\
\text { ment. }\end{array}$ & $\begin{array}{l}\text { Students were presented with three different design solutions } \\
\text { from the field trip and asked to calculate the amount of light } \\
\text { that passed through the "patches" as well as the associated } \\
\text { cost. They then used this information to make an informed } \\
\text { decision about the optimal design solution. }\end{array}$ \\
\hline
\end{tabular}

TABLE I. Overview of two modules

2 classes from an afterschool program for girls (grades 3 and 4, age 8-10) participated in 10 week after school programs at the museum which included both full modules (all 8 activities plus 2 additional days for exploring exhibits and completing pre and post assessments). The focal schools and afterschool program were selected to represent a broad range of demographics served by the museum field trip program. At school 1, $40 \%$ of the students were classified as English Language Learners and 62[24]. At School 2, 9\% were classified as English Language Learners and $11 \%$ qualified for free and reduced lunch. At school 3, 17.5\% were classified as English Language Learners and 51.8\% qualified for free and reduced lunch. The afterschool program served girls in the local area; $70 \%$ were eligible for free and reduced lunch.

Data focused on here included observations of classrooms that completed the complementary activities, observations of afterschool program, student work, pre/post questionnaires of teachers and science specialists $(\mathrm{n}=20)$, and interviews with a subset of teachers $(n=18)$, facilitator reflections, project team observations, and field notes. This data informed the iterative development of each module. Analysis of the module development process, which was qualitative and emergent, led to the design principles presented here. Both modules converged on similar structures through the iterative design processes which were identified and condensed into the eight design principles described below.

\section{DESIGN PRINCIPLES}

In this section, we present eight design principles based on the analysis of the development of the modules presented above. Principles 1-3 concern the field trip activity; principles $4-8$ focus on the development of classroom activities.
Design Principle 1: Design field-trip as a stand-alone activity. Not all teachers will implement the pre and post activities. Thus, the facilitators of the field trip program could not assume that students had completed them. Our testing phase, included classrooms that only attended a field trip to the museum and classrooms that participated in the field trip and the pre and post activities, providing us with opportunities to understand how the learning opportunities differed between these groups. Our goal for students who only participated in field trip programs was to experience an engineering design task related to a physical science phenomena. Specifically, we wanted students to identify goals and constraints of a problem, brainstorm solutions, and iterate on this solution. As such, the field trip program had to be designed to support student engagement in this engineering process with minimal previous exposure to engineering or the physics concept that informed the design challenge.

Design Principle 2: Field trip activities provides opportunities to engage with new tools/exhibits with minimal learning curve. To leverage the resources of the museum that differed from those of the classrooms, we thought it was important that the students had opportunities to make use of exhibits and specialized tools. However, the brief nature of field trips did not permit for extensive time to learn to use the materials and tools. Thus, the materials used required minimal amount of time to learn how to engage with the materials to fit within the time constraints of the field trip. For example, in Module 2, students used digital lux meters and thermometers that required only pressing a button and reading a digital measurement. This allowed students to focus their energy and time on engaging in the engineering design process.

Design Principle 3: Design field trips to be implemented similarly across a wide range of grade levels. Field trips to museums are sometimes scheduled with varying grade lev- 
els attending on the same day, thus requiring museum staff to offer programs for multiple grade levels back to back. Due to time constraints within the museum space, the field trip programs had to be designed to meet the needs of different grade levels without having to take down and set up the materials for a new program. Field trips leveraged the same material set up, but increased the complexity of the design challenge for higher grade levels. For example, kindergarteners who participated in the Riding the Rising Air module were challenged to develop a craft to hover or stay in the middle of the wind column while holding a penny. Fifth and sixth graders were presented with a similar design challenge; however, their challenge was situated in the context of monitoring a wildfire- a common occurrence in the local area. Students aimed to design a craft that could hover above a wildfire while holding a penny-sized sensor. They used the materials available in the museum space to represent the conditions of the fire and the sensor. The activities that the students engaged in were nearly identical. By offering similar programs across multiple grade levels, the amount of training time required for museum staff was also reduced.

Design Principle 4: Design complementary schoolbased activities to require only materials that are easy to access. Through interviews about teacher experiences with science and engineering in their classroom and what resources or knowledge they would need to implement these activities, a common comment was that teachers lacked time to gather and prep materials. Thus, classroom activities used only easy-to-access materials. Even so, we found that available materials differed across classrooms. To accommodate these differences and reduce prep time required to acquire materials, we provided alternative materials for each activity. For example, in the Riding the Rising Air module, the first classroom activity used deli paper, string, washers, and masking tape. Alternative materials included newspaper, tissue paper or butcher paper (instead of deli paper) and pennies or small counting blocks (instead of washers).

Design Principle 5: Align complementary school-based activities with grade level Literacy and Math Standards. Unlike the field trip program that needed to be implemented similarly across grade levels, teachers could implement a classroom activity more tailored to their grade level. Thus, each of these modules were differentiated across broad grade level bands (see [25]); however, through iterative testing and discussions with teachers, we found the largest difference between grade levels was not in student science or engineering knowledge, but in their literacy and math capabilities. Using the literacy and math standards to guide our differentiation allowed us to do more age-appropriate activities, especially in the ways that students collected and analyzed data. We incorporated opportunities in each classroom lesson for students to reflect and write or draw about the physics phenomenon they were working with or the engineering design solutions they had created. In addition, the post-activity connected to student math standards. Figure 1 shows student work from the Greenhouse on the Moon module at the 6th grade level. Fig-
A)


placed over an image. I don't really know why this hoppens
but this is what I think is happening. Since
ourmarkers aren't the exact shade of
the filter it makes adifferent impact
on the color. Usually red and yellow is
orangesut ince it's not the same shade

B)



FIG. 1. Example of literacy (1A) and mathematics (1B) connections within the Greenhouse on the Moon module.

ure $1 \mathrm{~A}$ is an example of student written explanations of the phenomenon they were investigating in the first classroom pre-activity while Figure 1B shows a mathematical analysis of their design solutions from the field trip activity focusing on the percent of light that passed through each filter as well as a cost analysis of each design solution to better inform the optimization process. Teachers expressed appreciation of these connections to other standards and mentioned that they used these activities as starting points for lessons in these other content areas.

Design Principle 6: Design complementary schoolbased activities so that science investigations precede engineering tasks. To encourage thoughtful design rather than trial and error, we preceded engineering design tasks with a science investigation that explored the relationship between variables that related to the planned engineering task. For example, in the Greenhouse on the Moon module, prior to the engineering field trip activity which focused on combining materials (e.g., acrylic, colored films, plastic) in a way that allowed transmission of a specific amount of infrared heat and visible light, students observed and recorded which colors of light red and blue allowed through. Figure 2 shows an example of student data recorded in this first pre-activity which used in the second activity done in their class.

Design Principle 7: Design engineering activity for complementary school-based activity to follow the same general design process as field trip. With engineering being a new subject area for many students, we found it beneficial to support student engagement with, and learning of, the engineering design process through scaffolded design challenges in the pre-activities. Students were presented with a simplified engineering design challenge that followed the same design process as the field trip activity. For example, with the Riding the Rising Air module, the second pre-activity challenged students to design a craft that slowed the fall of a 


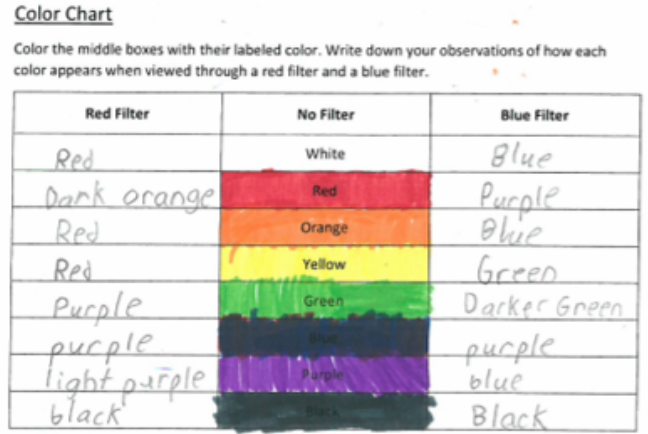

FIG. 2. Student data collection tool in the Greenhouse on the Moon module.

washer, whereas the field trip asked students to design a craft that hovered in an upward column of moving air. In both cases (the classroom and field trip) they first define and delimit the problem, developed solutions and then optimized those solutions. The classroom activity scaffolded the engineering design process with whole class discussions after each step to encourage reflection and support student ideas. This allowed students to have a guided introduction into the engineering design process to inform the field trip activity and prepared students to engage in this task.

Design Principle 8: Integrate building models of phenomena in complementary school-based activities. A critical practice within the NGSS practices is that of developing and using models (NGSS Practice 2) [26] [27]. Articulating through words and drawings the visible and invisible mechanisms that drive phenomena is vital to students' content learning. Even more important is the process of revising these models in the face of new evidence. The limited time coupled with the novel environment of field trip experiences makes field trips less than ideal for providing sufficient opportunities for students to develop and revise models. Thus, this practice is incorporated into the classroom activities that occur both prior to and after the field trip experience. Classrooms allow for repeated experience with the same phenomena, facilitating model development. Figure 3 shows two student examples of the conceptual models developed in the first pre-activity in the Greenhouse on the Moon module. These models were revisited throughout the subsequent activities and revised to reflect student learning.

\section{DISCUSSION}

These eight design principles were derived from our iterative development and implementation process and also serve to inform future development. Of particular importance to this process was the contribution of voices from stakeholders from multiple institutions. Project meetings around develop- ment included university faculty and graduate students with experience in physics education research, physics curriculum What's Happening?

Write or draw what you think happens when a red or blue filter is placed over an image.



FIG. 3. Example of student work from the Greenhouse on the Moon module depicting their conceptual models of filters

design, and elementary teacher education; museum facilitators who worked directly with field trip programs; museum curriculum developers, and museum leadership who oversaw all programming. Classroom teachers participated in extensive interviews and surveys and students' ideas came through their observed participation and work.

In our case, the design principles focused on providing practice-based learning experiences that linked school-based experiences and field trip experiences by supporting student engagement in the practices of science and engineering, thus contributing to the development of STEM identities. While designed to include both physics and engineering, these design principles can be applied to a diverse range of IPER contexts. They could be leveraged by both museum professionals interested in extending the learning of their field trip programs or teachers creating materials that complement field trip and outreach activities. These design principles can also be used as a model for other organizations embarking on developing research-practice partnerships to guide program development that supports learning across multiple contexts. Working across institutions is challenging. Developing shared language, goal, and design principles can support the development of productive partnerships between physics departments, museums, and schools.

Our future work includes using these design principles to develop modules on resonance frequencies and buildings, wind energy, and electricity and light. In addition our next steps for all modules will be to integrate teacher supports and resources, which will require a new set of design principles informed by teacher learning.

\section{ACKNOWLEDGMENTS}

This material is based upon work supported by the National Science Foundation (grant EEC-1824856; EEC-1824859) 
[1] C. Fracchiolla, N. Finkelstein, and K. Hinko, Characterizing models of informal physics programs, in Physics Education Research Conference (2019).

[2] D. Harlow and R. Skinner, Museum-based physics education research through research practitioner partnerships, Proceedings of 2019 Annual Meeting of Physics Education Conference (2019).

[3] S. Bergin, Reflections on informal physics education, in Physics Education Research Conference 2019, PER Conference Plenary Paper (Provo, UT, 2019).

[4] J. Bell, Informal stem education: From personal to professional, in Physics Education Research Conference 2019, PER Conference Plenary Paper (Provo, UT, 2019).

[5] N. R. Council et al., Identifying and supporting productive STEM programs in out-of-school settings (National Academies Press, 2015).

[6] N. Scienceand T. Council, Charting a course for success: Americaâs strategy for stem education (2018).

[7] D. Harlow, R. Skinner, A. Hansen, J. Nation, J. Pulgar, A. Spina, A. McLean, C. Barriault, and A. Prud'hommeGenereux, Creating stem learning opportunities through partnerships, Handbook of Research on STEM Education (edited by C. Johnson, M. Mohr-Schroeder, T. Moore, L. Bryan and L. English (2020).

[8] M. L. Nabors, L. C. Edwards, and R. K. Murray, Making the case for field trips: What research tells us and what site coordinators have to say., Education 129 (2009).

[9] D. Andersonand Z. Zhang, Teacher perceptions of field-trip planning and implementation, Visitor Studies Today 6, 6 (2003).

[10] J. Kisiel, Understanding elementary teacher motivations for science fieldtrips, Science Education 89, 936 (2005).

[11] J. DeWitt and M. Storksdieck, A short review of school field trips: Key findings from the past and implications for the future, Visitor studies 11, 181 (2008).

[12] D. Anderson, K. B. Lucas, I. S. Ginns, and L. D. Dierking, Development of knowledge about electricity and magnetism during a visit to a science museum and related post-visit activities, Science Education 84, 658 (2000).

[13] H. Lee, M. J. Stern, and R. B. Powell, Do pre-visit preparation and post-visit activities improve student outcomes on field trips?, Environmental Education Research , 1 (2020).

[14] J. H. Falk and L. M. Adelman, Investigating the impact of prior knowledge and interest on aquarium visitor learning, Journal of research in science teaching 40, 163 (2003).

[15] M. J. Stern, R. B. Powell, and N. M. Ardoin, What difference does it make? assessing outcomes from participation in a res- idential environmental education program, The Journal of Environmental Education 39, 31 (2008).

[16] C. M. Cunningham and G. J. Kelly, Epistemic practices of engineering for education, Science Education 101, 486 (2017).

[17] E. Tan, A. Calabrese Barton, H. Kang, and T. O'Neill, Desiring a career in stem-related fields: How middle school girls articulate and negotiate identities-in-practice in science, Journal of Research in Science Teaching 50, 1143 (2013).

[18] NGSSLeadStates, Next generation science standards: For states, by states, Appendix D: All standards, all students: Making the Next Generation Science Standards accessible to all students (2013).

[19] C. E. Coburn, W. R. Penuel, and K. E. Geil, Practice partnerships: A strategy for leveraging research for educational improvement in school districts., William T. Grant Foundation (2013).

[20] B. J. Fishman, W. R. Penuel, A.-R. Allen, B. H. Cheng, and N. Sabelli, Design-based implementation research: An emerging model for transforming the relationship of research and practice, National society for the study of education 112, 136 (2013).

[21] W. R. Penuel, B. J. Fishman, B. Haugan Cheng, and N. Sabelli, Organizing research and development at the intersection of learning, implementation, and design, Educational researcher 40, 331 (2011).

[22] A. Muller, T. Connolly, R. Skinner, and D. Harlow, Extending learning of engineering beyond the field trips, Science and Children (in print).

[23] D. B. Harlow, R. Skinner, T. Connolly, and A. Muller, Partnering to develop a coordinated engineering education program across schools, museum field trips, and afterschool programs, Connected Science Learning 2 (2020).

[24] U. States, Elementary and secondary education act of 1965 (esea) (1965).

[25] A. Muller, T. Connolly, R. Skinner, and D. Harlow, Designbased research project to develop a science and engineering education program linking field trip experiences to classroom experience, Proceedings of 2019 Annual Meeting of Physics Education Conference (2019).

[26] M. Windschitl, J. Thompson, and M. Braaten, Beyond the scientific method: Model-based inquiry as a new paradigm of preference for school science investigations, Science education 92, 941 (2008).

[27] M. Windschitl, J. Thompson, and M. Braaten, Ambitious science (Boston, MA: Harvard Education Press, 2018). 